Supplement of Biogeosciences, 17, 5861-5882, 2020 https://doi.org/10.5194/bg-17-5861-2020-supplement (C) Author(s) 2020. This work is distributed under the Creative Commons Attribution 4.0 License.

(c) (1)

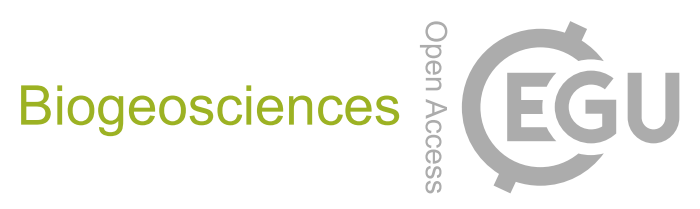

Supplement of

\title{
Investigating the sensitivity of soil heterotrophic respiration to recent snow cover changes in Alaska using a satellite-based permafrost carbon model
}

Yonghong Yi et al.

Correspondence to: Yonghong Yi (yonghong.yi@jpl.nasa.gov)

The copyright of individual parts of the supplement might differ from the CC BY 4.0 License. 


\section{Model description}

\section{(1) The remote sensing driven permafrost model (RS-PM)}

The remote sensing based permafrost model, as described in Yi et al. (2018; 2019) uses a numerical approach to simulate soil temperature and soil freeze/thaw (F/T) processes (and changes in soil liquid water content) along the $60 \mathrm{~m}$ soil profile using 23 soil layers, with finer vertical resolution at the surface and increasing layer thickness at depth. The soil nodes of $0-1 \mathrm{~m}$ are distributed at $0.01,0.03,0.08,0.13$, $0.23,0.33,0.45,0.55,0.70$, and $1.05 \mathrm{~m}$ depths. Multiple snow layers are used to simulate snow insulation effects, accounting for changes in snow density and thermal properties due to seasonal snow cover evolution. The snow thermal properties, including heat capacity and thermal conductivity, are empirically estimated from snow density (Calonne et al., 2011). External model inputs include the upper boundary temperature conditions, total soil moisture content, and snow depth and density. Model outputs include soil temperature and unfrozen liquid water fraction along the soil profile, which is also used to define the soil F/T state.

The following 1-D heat transfer equation with phase change is used to simulate the snow and ground thermal dynamics:

$$
\begin{aligned}
& C \frac{\partial}{\partial t} T(z, t)+L \zeta \frac{\partial}{\partial t} \theta(T, z)=\frac{\partial}{\partial z}\left(\lambda \frac{\partial}{\partial z} T(z, t)\right), \\
& z \in\left[z_{s}, z_{b}\right]
\end{aligned}
$$

where $T(z, t)$ is the temperature $\left({ }^{\circ} \mathrm{C}\right)$ at a specific soil depth $(z)$ and time step $(t), L$ is the latent heat of fusion of water $\left(\mathrm{J} \mathrm{m}^{-3}\right), \zeta$ is the total soil water content $\left(\mathrm{m}^{3} \mathrm{~m}^{-3}\right)$, and $\theta$ is the unfrozen liquid water fraction (\%). $C$ and $\lambda$ are the volumetric heat capacity $\left(\mathrm{J} \mathrm{m}^{-3} \mathrm{~K}^{-1}\right)$ and thermal conductivity $\left(\mathrm{W} \mathrm{m}^{-1} \mathrm{~K}^{-1}\right)$ of soil, respectively, varying with depth, soil moisture and F/T state. The upper boundary condition is set as the surface temperature at the snow/ground surface $\left(z_{s}\right)$, while a heat flux characterizing the geothermal gradient is applied at the lower boundary $\left(z_{b}=60 \mathrm{~m}\right)$. The soil thermal properties, including the soil heat capacity and thermal conductivity, are a function of the thermal properties of mineral and organic soil solid and liquid water, and ice components, weighted by their volumetric fraction.

The thermal conductivity $\lambda$ is estimated as a normalized thermal conductivity of the dry $\left(\lambda_{d r y}\right)$ and saturated $\left(\lambda_{\text {sat }}\right)$ soil thermal conductivity, weighted by soil saturation:

$\lambda=K_{e} \lambda_{\text {sat }}+\left(1-K_{e}\right) \lambda_{d r y}$

where the Kersten number $\left(K_{e}\right)$ is a function of the soil saturation degree, using a logarithm form for unfrozen soils and linear form for frozen soils (Farouki, 1981; Lawrence and Slate, 2008). $\lambda_{d r y}$ is estimated from the soil bulk density; $\lambda_{\text {sat }}$ is estimated as a geometric mean of the thermal conductivity of different soil components (Farouki 1981), including mineral and organic soil solid, liquid water and ice, which can vary several-fold from pure organic soil $\left(\sim 0.5 \mathrm{~W} \mathrm{~m}^{-1} \mathrm{~K}^{-1}\right)$ to mineral soils $\left(1.5 \sim 3 \mathrm{~W} \mathrm{~m}^{-1} \mathrm{~K}^{-1}\right)$. 
Soil water usually freezes at a sub-zero temperature depending on solute concentration and other factors, and the model uses the following empirical function to estimate the unfrozen liquid water fraction $(\theta)$ :

$\theta=\left\{\begin{array}{cc}1 & T \geq T_{*} \\ \left|T_{*}\right|^{b}|T|^{-b} & T<T_{*}\end{array}\right.$

The constant $T_{*}$ represents the freezing point depression, with values generally above $-1{ }^{\circ} \mathrm{C}$ (Woo, 2012).

$b$ is a dimensionless parameter determined by fitting the unfrozen water curve, which can vary significantly depending on soil type (Schaefer and Jafarov, 2016).

\section{References:}

Calonne, N., Flin, F., Morin, S., Lesaffre, B., du Roscoat, S. R. and Geindreau, C.: Numerical and experimental investigations of the effective thermal conductivity of snow, Geophysical Research Letters, 38, L23501, doi:10.1029/2011GL049234, 2011.

Farouki, O.T.: Thermal properties of soils, Report No. 81(1), CRREL Monograph, 1981.

Lawrence, D. M. and Slater, A. G.: Incorporating organic soil into a global climate model, Climate Dynamics, 30, 145-160, 2008.

Rawlins, M. A., Nicolsky, D. J., McDonald, K. C., and Romanovsky, V. E.: Simulating soil freeze/thaw dynamics with an improved pan-Arctic water balance model, Journal of Advances in Modeling Earth Systems, 5, 659-675, 2013.

Schaefer, K. and Jafarov, E.: A parameterization of respiration in frozen soils based on substrate availability, Biogeosciences, 13(7), 1991-2001, doi:10.5194/bg-13-1991-2016, 2016.

Woo, M. K.: Permafrost hydrology, Heidelberg, Germany: Springer-Verlag, 575 pp, 2012.

Yi, Y., Kimball, J. S., Chen, R. H., Moghaddam, M., Reichle, R. H., Mishra, U., Zona, D. and Oechel, W. C.: Characterizing permafrost active layer dynamics and sensitivity to landscape spatial heterogeneity in Alaska, The Cryosphere, 12(1), 145-161, doi:10.5194/tc-12-145-2018, 2018.

Yi, Y., Kimball, J. S., Chen, R. H., Moghaddam, M. and Miller, C. E.: Sensitivity of active-layer freezing process to snow cover in Arctic Alaska, The Cryosphere, 13(1), 197-218, doi:10.5194/tc-13-197-2019, 2019. 


\section{Supplementary tables and figures}

Table S1 Main parameters prescribed for each biome type in the carbon model, including maximum light use efficiency $\left(\varepsilon_{\max }\right)$, carbon use efficiency (CUE), the extinction coefficient of root distribution $(\beta)$, fraction (percentage) of leaf, fine root and woody components of litterfall.

\begin{tabular}{ccccccc}
\hline Biome type & $\begin{array}{c}\varepsilon_{\max } \\
\left(\mathrm{g} \mathrm{C} \mathrm{MJ}^{-1}\right)\end{array}$ & CUE & $\beta^{*}$ & Leaf (\%) & $\begin{array}{c}\text { Fine roots } \\
(\%)\end{array}$ & Wood (\%) \\
\hline Grasslands/Herbaceous & 0.50 & 0.60 & 0.914 & 32 & 48 & 20 \\
Scrub/Shrub & 0.78 & 0.575 & 0.930 & 28 & 42 & 30 \\
Forest & 1.05 & 0.55 & 0.943 & 24 & 36 & 40 \\
Wetland & 1.00 & 0.60 & 0.914 & 36 & 54 & 10 \\
Croplands & 1.20 & 0.60 & 0.914 & 28 & 42 & 30 \\
\hline
\end{tabular}

* The vertical root distribution was defined as in Jackson et al. (1996): $\gamma=1-\beta^{z}$, where $\gamma$ is the cumulative root fraction from soil surface to depth $\mathrm{z}(\mathrm{cm})$, and $\beta$ is the extinction coefficient parameter. 

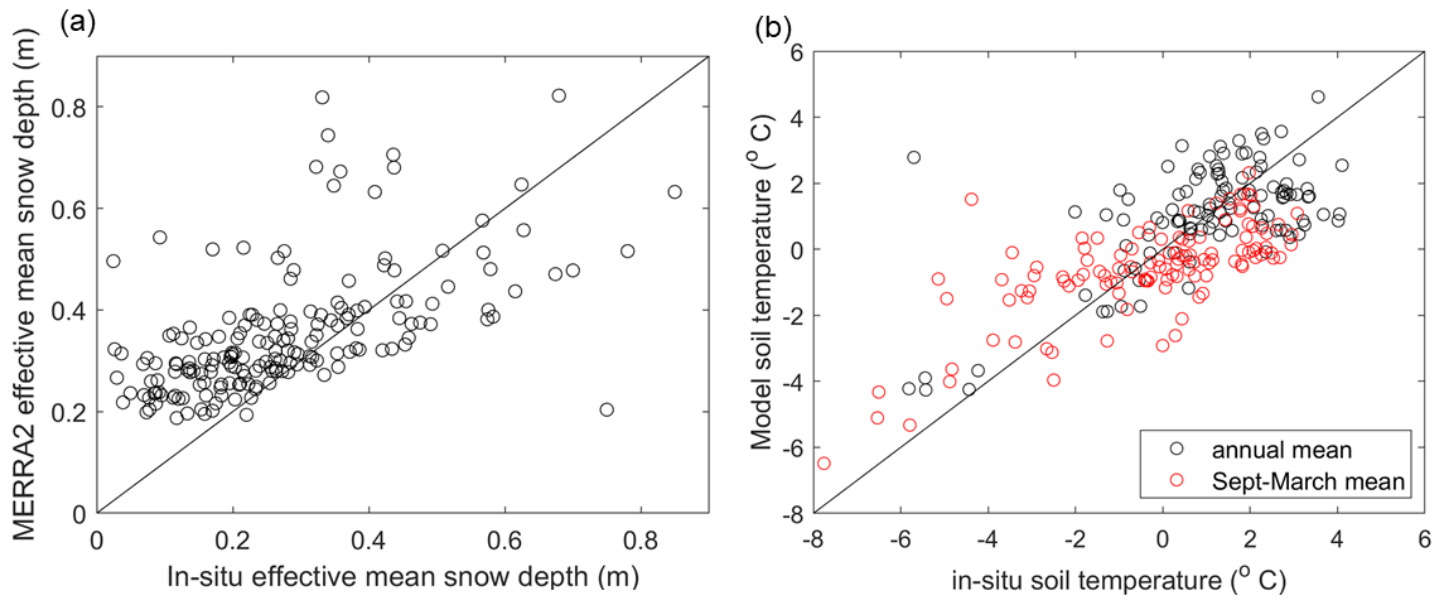

Fig. S1 Comparison between effective snow depth (a) derived from in-situ observations at Snotel sites and downscaled MERRA2 data, and observed and model simulated monthly soil temperature at $20 \mathrm{~cm}$ depth (b). Note that the sites compared for snow depth and soil temperature may be inconsistent due to inconsistency in the snow depth and soil temperature measurements at the Snotel sites. Generally, there are more snow depth measurements than soil temperature measurements. 


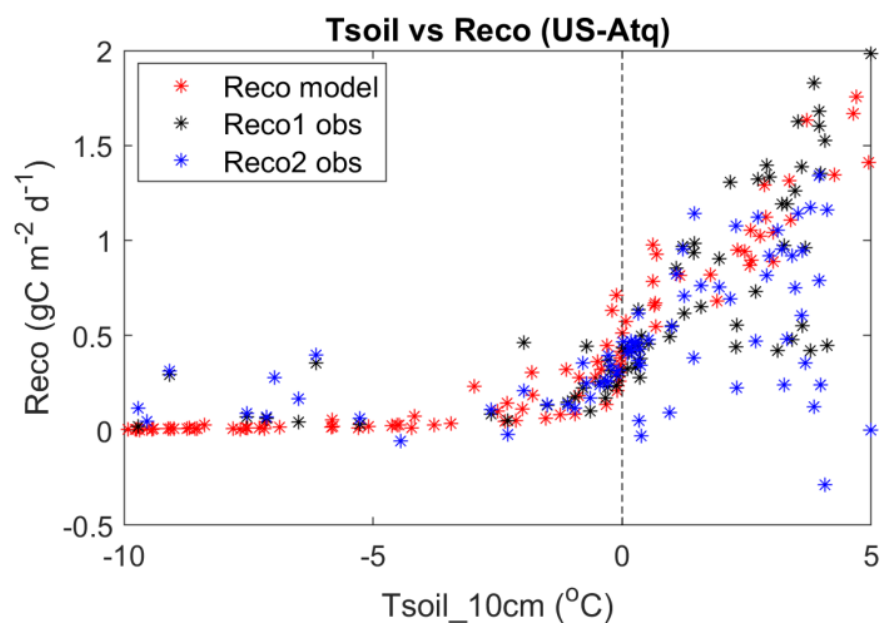

Fig. S2 Model simulated temperature sensitivity of ecosystem respiration at the US-Atq tundra site. "Reco1 obs" and "Reco2 obs" represent ecosystem respiration estimates derived using tower-based NEE measurements and different partitioning methods provided by the tower PI. 

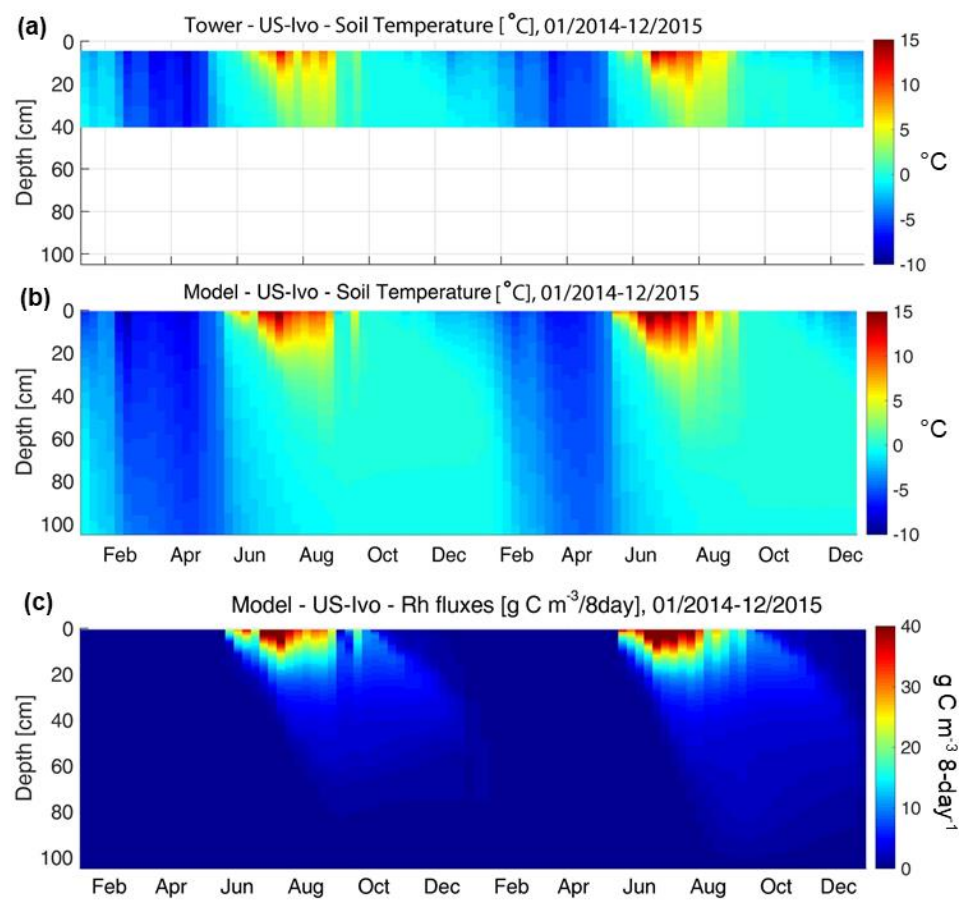

Fig. S3 Model simulated soil temperature and heterotrophic respiration ( $R$ h) flux density profile compared with in-situ soil temperature profile measurements (up to $40 \mathrm{~cm}$ ) at the US-Ivo tundra site from 2014 to 2015. 

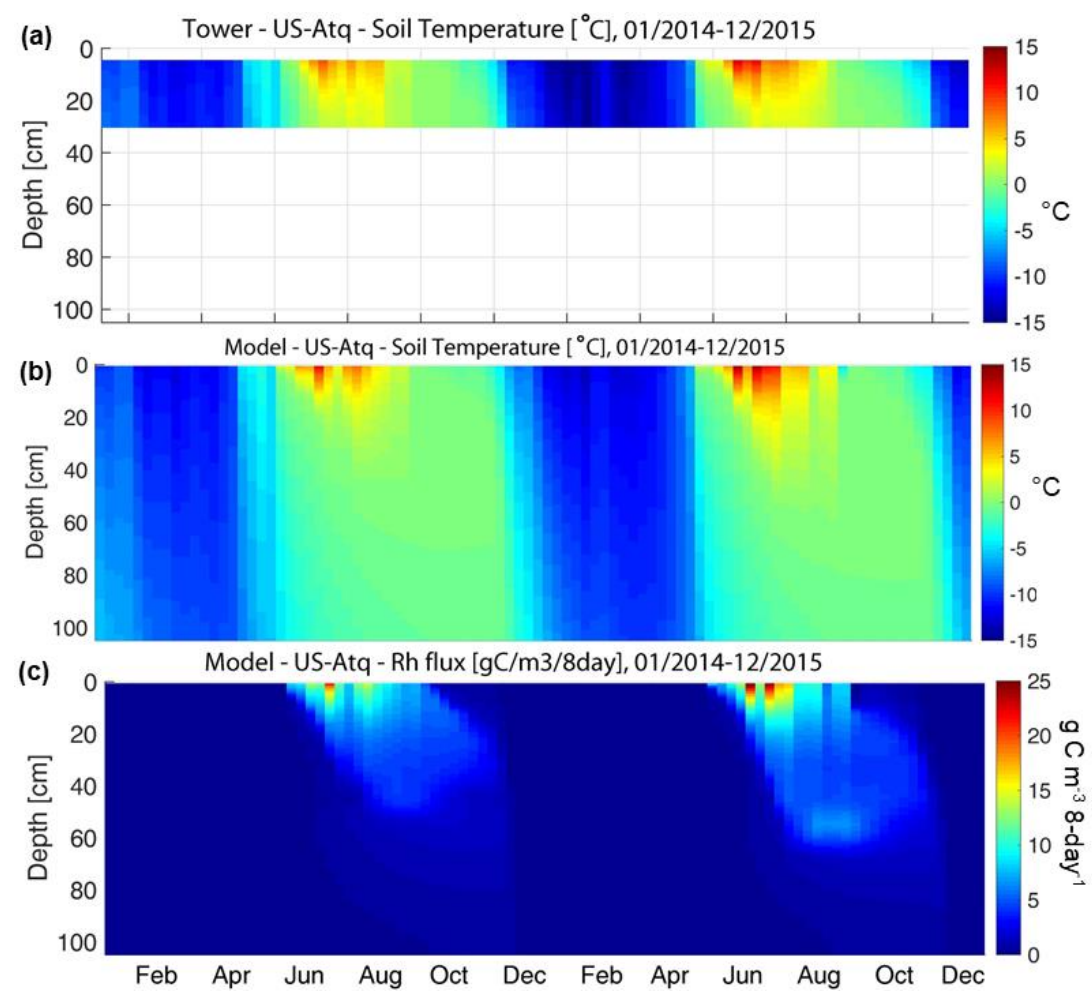

Fig. S4 Model simulated soil temperature and heterotrophic respiration (Rh) flux density profile, compared with in-situ soil temperature profile measurements (up to $30 \mathrm{~cm}$ ) at the US-Atq tundra site from 2014 to 2015. 

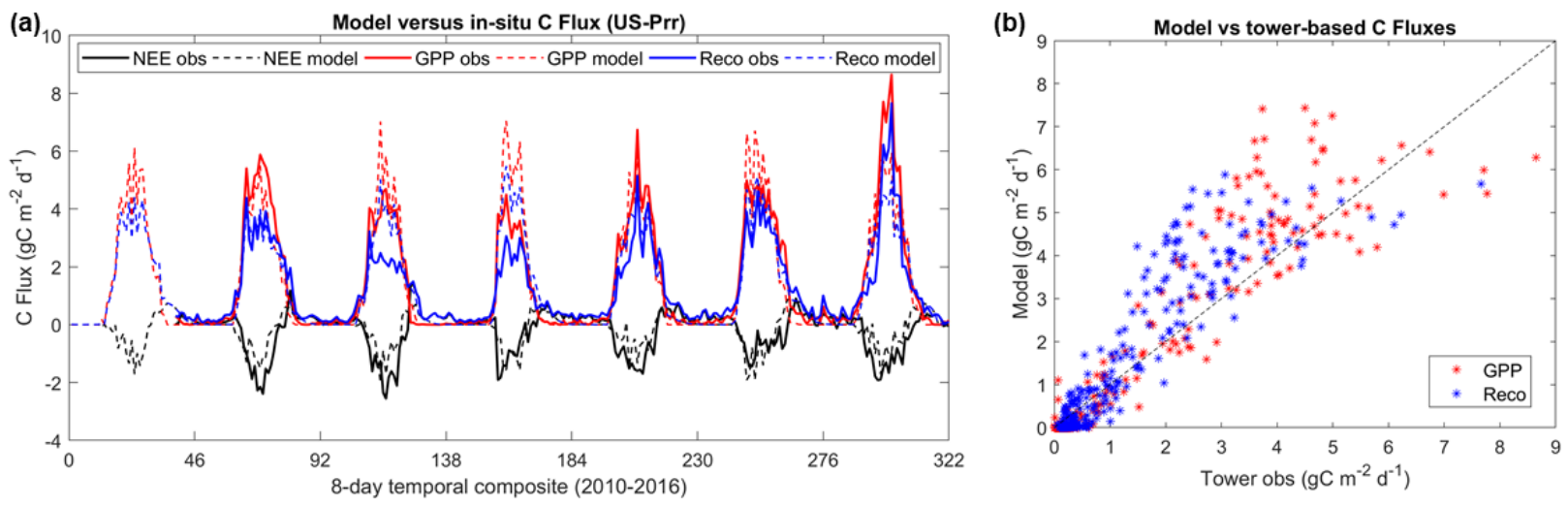

Fig. S5 Comparison of model simulated carbon fluxes with EC tower-based NEE measurements and GPP/Reco estimates at the US-Prr boreal forest site. 

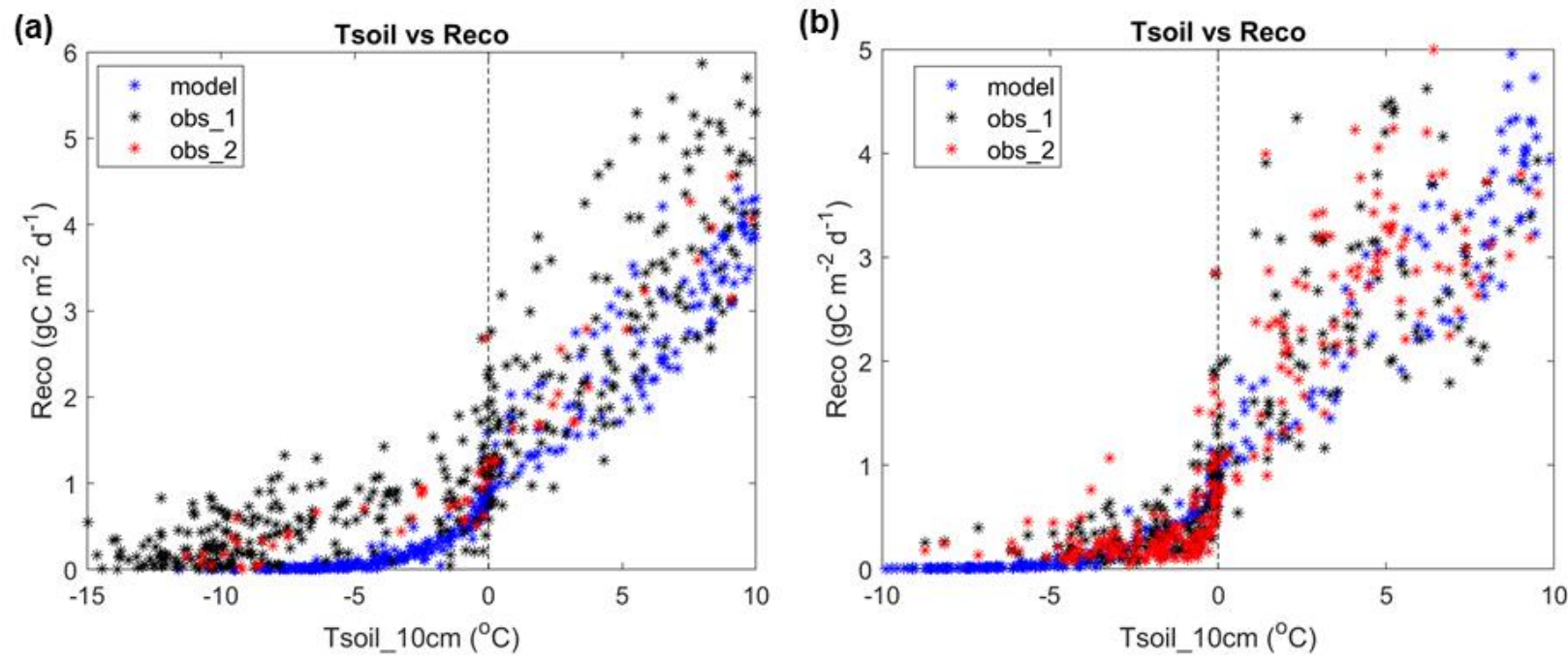

Fig. S6 Relationship between soil temperature (Tsoil) at $\sim 10 \mathrm{~cm}$ depth and Reco at the two boreal forest sites: (a) US-Uaf: obs_1 and obs_2 use Tsoil measurements at different soil nodes. At this site, only one set of GPP and Reco estimates was provided by the tower PI. (b) US-Prr: obs_1 and obs_2 use towerbased Reco estimates derived from NEE observations and different partitioning methods provided by the tower PI. 


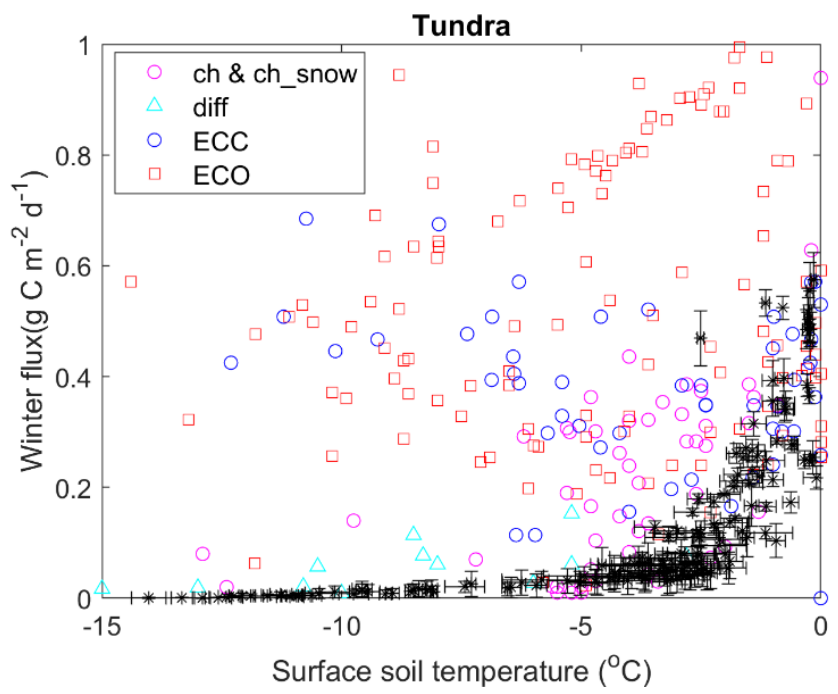

Fig. S7 Effects of soil temperature on winter $\mathrm{CO}_{2}$ fluxes at all Alaskan tundra sites using the in-situ synthesis data collected from different methods (Natali et al. 2019b). EC-open path (ECO) measurements show a large scattering in the temperature response of winter flux than the other methods. The model simulated temperature response of winter soil respiration is indicated by Asterisk symbols. The error bars indicate the standard deviations of model simulations using different values $(0.35 \sim 0.9)$ for the dimensionless parameter characterizing the unfrozen water curve for most soil types. 


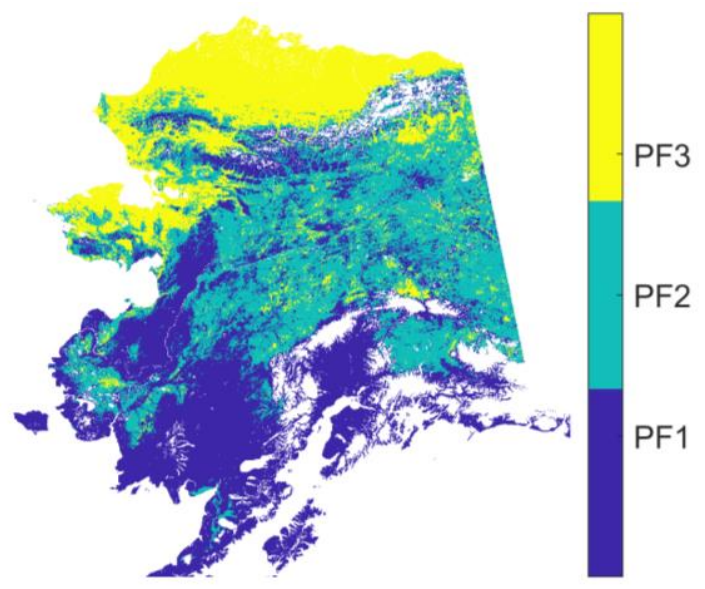

Fig. S8 The permafrost zonal map in Alaska, based on an ancillary permafrost map (Pastick et al., 2015), including permafrost frequency ranging from 0 to $33.3 \%$ (PF1), $33.3 \%$ to $66.7 \%$ (PF2), and $66.7 \%$ to $100 \%$ (PF3). 
(a) Trends of MODIS snow-free period (days $\mathrm{yr}^{-1}$ )

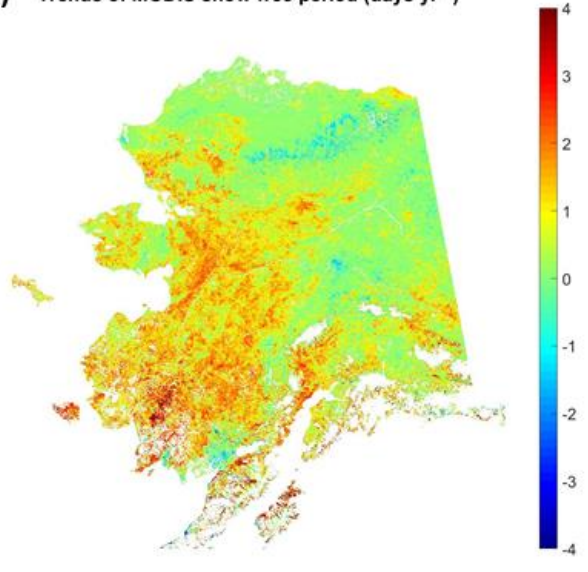

(b)

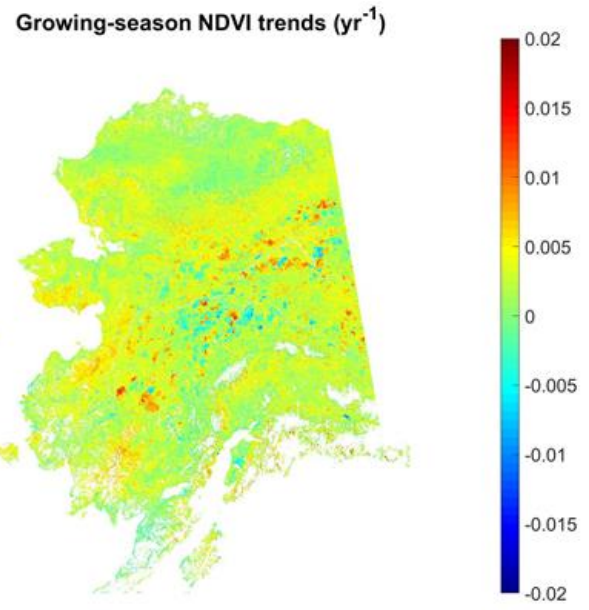

Fig. S9 Annual GPP trends are mostly explained by a longer growing season (or snow-free season, a) and positive NDVI trends (b) during the growing season (May-September) from 2001 to 2017. The snow-free period in panel (a) was derived from MODIS SCE data. 


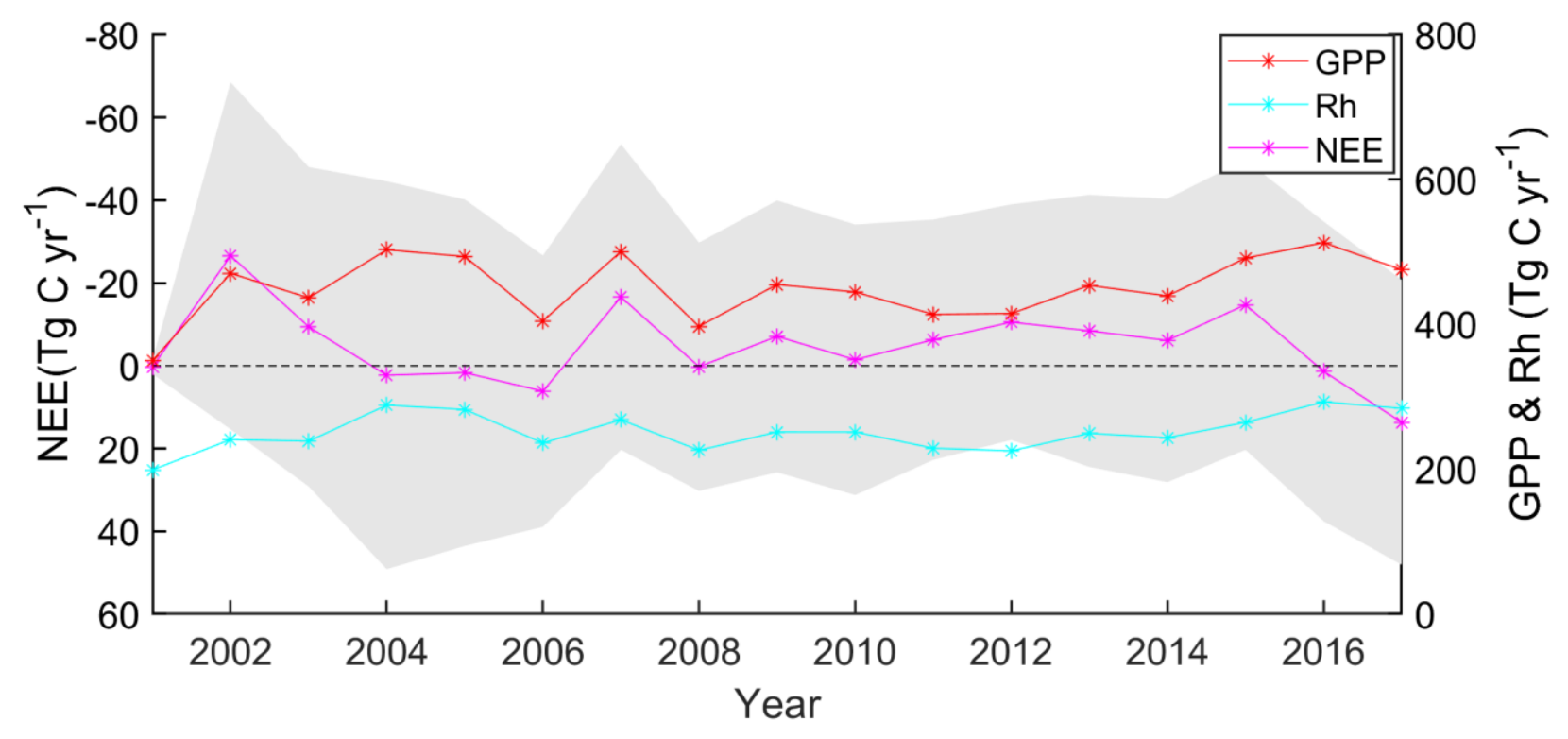

Fig. S10 Time series of annual carbon fluxes summed over the Alaska study area $\left(\sim 1.21\right.$ million $\left.\mathrm{km}^{2}\right)$ from 2001 to 2017. Gray shading denotes the standard deviation of estimated annual NEE flux over the study area. A very low standard deviation of NEE flux in 2001 was due to the model steady state assumption in the spin up year (2001). The standard deviation of GPP and Rh flux across the study area was approximately $50 \%$ of the regional mean, and was not shown. 
(a)

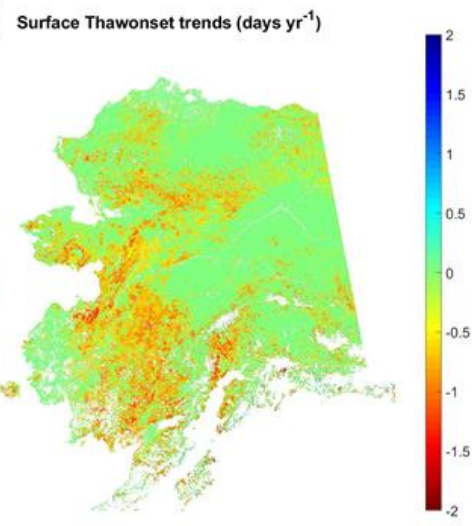

(d)

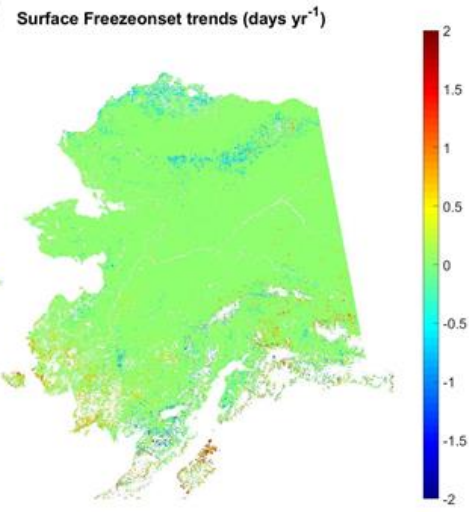

(b)

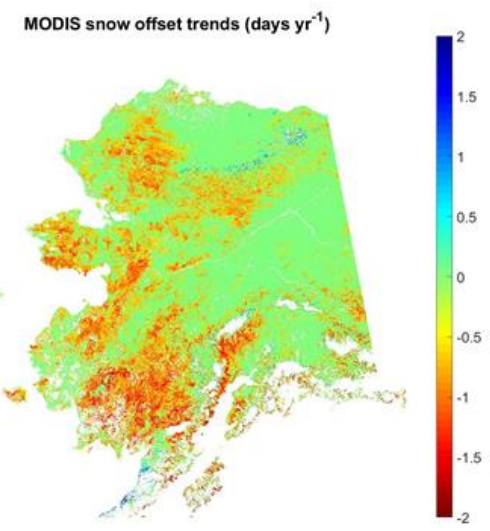

(e)

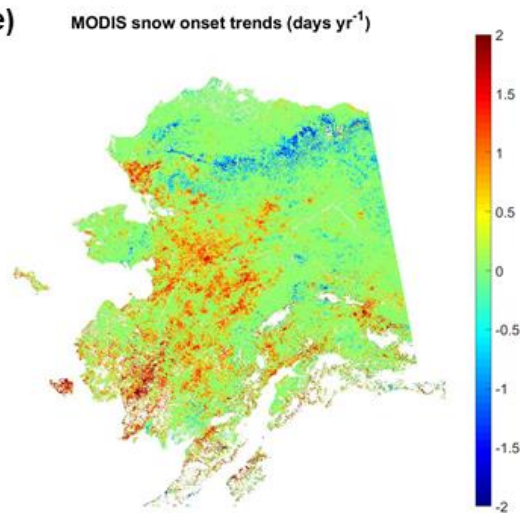

(c)

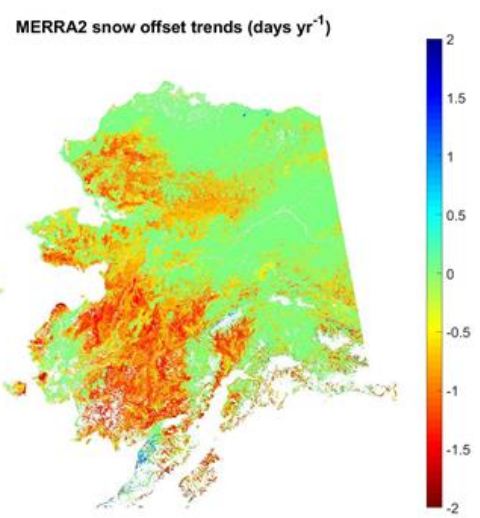

(f)

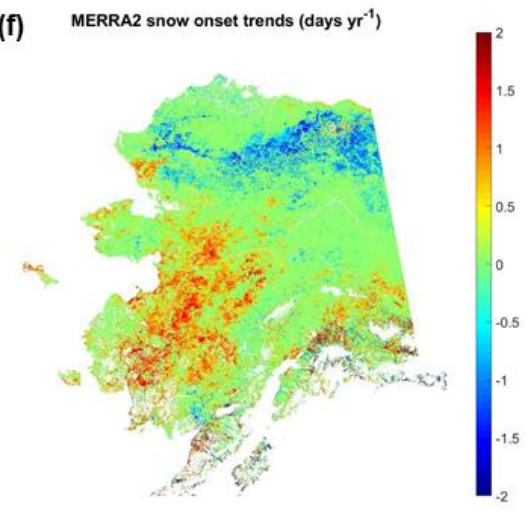

Fig. S11 Temporal (2001-2017) trends of surface freeze/thaw onset derived from MODIS LST data (a, d), snow offset/onset derived from MODIS SCE (b, e), and downscaled MERRA2 snow depth data (c, f). The timing of snow disappearance (i.e. snow offset) in the spring was defined as the center of the 8-day composite period being snow free, and with mean snow depth less than $5 \mathrm{~cm}$ depth within a 24-day moving window. 
(a)

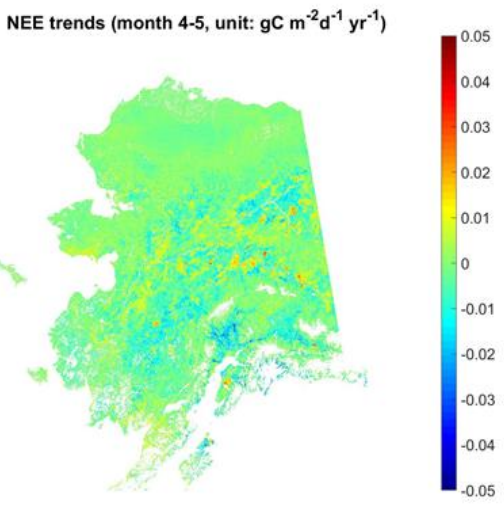

(b)

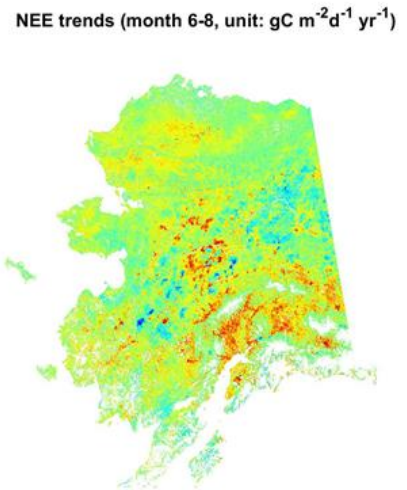

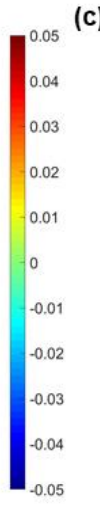

(c)

NEE trends (month 9-11, unit: $\mathrm{gC} \mathrm{m}^{-2} \mathrm{~d}^{-1} \mathrm{yr}^{-1}$ )

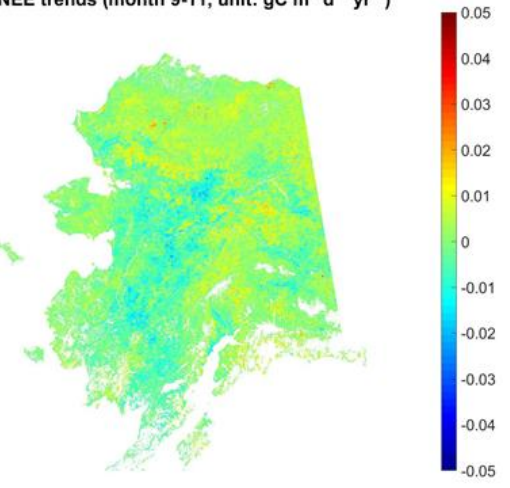

Fig. S12 Temporal (2001-2017) trends of model simulated seasonal NEE flux from: (a) April to May, (b) June to August; and (c) September to November. Positive NEE trends indicate decreasing net carbon uptake activity, while negative NEE trends indicate enhanced net carbon uptake. 

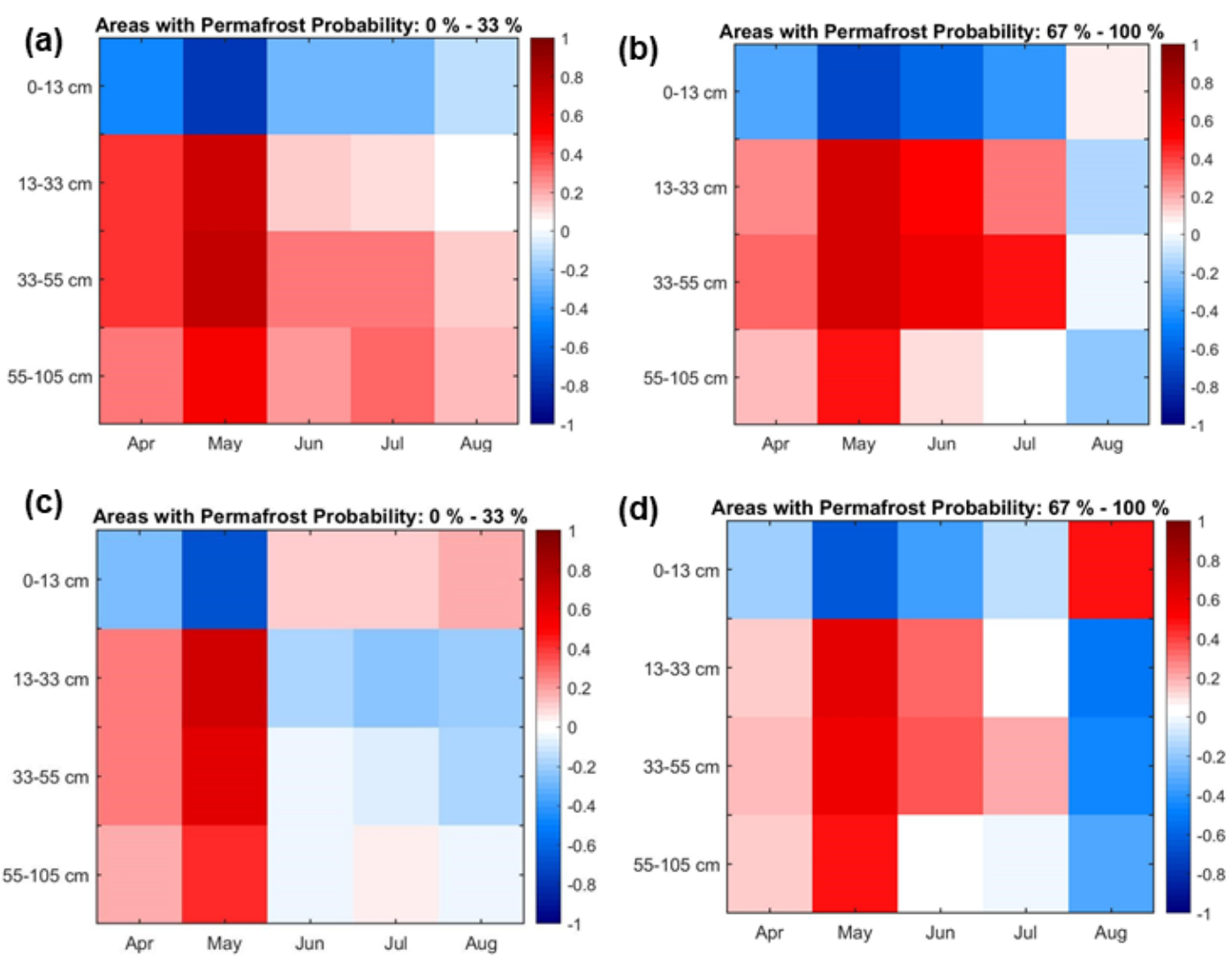

Fig. S13 Correlation analysis between model estimated Rh fraction from different soil depths during the summer season (June-August) and monthly MODIS LST for different permafrost regions: (a-b): Pearson correlation coefficient; (c-d) partial correlation between LST and Rh fraction, using growing-season (April-August) GPP as the controlling variable. 